\title{
The floral biology of the olive: effect of flower number, type and distribution on fruitset
}

\author{
S. Lavee ${ }^{\text {a, }}{ }^{*}$, L. Rallo ${ }^{b}$, H.F. Rapoport ${ }^{c}$, A. Troncoso ${ }^{d}$ \\ a Volcani Center, Bet Dagan and Hebrew University of Jerusalem, Rehovot, Israel \\ ${ }^{\mathrm{b}}$ University of Córdoba, Córdoba, Spain \\ c IAS-CSIC, Córdoba, Spain \\ 'IRNAS-CSIC, Sevilla, Spain
}

\begin{abstract}
The effect of flower number and distribution on the fruiting behavior of various olive cultivars was studied over a period of 10 years. The number of staminate flowers within each cultivar had no significant effect on fruitset. Pre-bloom removal of up to $50 \%$ of the flowers did not affect fruitset. Variation in prebloom flower-removal position resulted in similar fruitset per inflorescence, whether flowers were removed along the inflorescence axis or from the distal half of each inflorescence. Removal of half of the inflorescences resulted in doubling the fruit set on the remaining ones, except in cv. Koronaiki which normally sets more than one fruit on most of its inflorescences. The distal fruitful inflorescence set more than one fruit (mostly two) on $70-80 \%$ of the shoots of various cultivars.

In cv. Santa Caterina a clear increase in fruitset per shoot was observed when $80 \%$ of the flowers per inflorescence were removed. In this cultivar the lateral flowers were significantly more fruitful than the king flower. This however, was not the case with cv. Manzanillo.
\end{abstract}

Keywords: Olive; Floral biology; Fruitset

\section{Introduction}

The olive tree produces an abundant number of flowers but only a small percent of those set normal fruits. Troncoso et al. (1978) specified that $25 \%$ of the ovaries are retained after petal drop, but only $2 \%$ of the floral population develops fruits which 
reach maturity. It was stated by Griggs et al. (1975) and is generally accepted that normal fruit development from $1 \%$ of the entire flower population is enough to ensure a good commercial crop. Rallo and co-workers (Rallo et al., 1981; Rallo and FernándezEscobar, 1985) showed that the major reduction in fruit number occurs during a period of 5-7 weeks after full bloom. This was confirmed by anatomical studies (Rapoport and Rallo, 1991).

Although pre-bloom phenomena such as pistil abortion (Uriu, 1959) and embryo sac development (Rallo et al., 1981; Rapoport and Rallo, 1991) have been considered, most studies on fruitset and production potential of the olive deal with the post-anthesis period. Thus the level of normal fruitset in most cases is based on heavily blooming trees in their ' $\mathrm{ON}$ ' year. This raises the question whether in years with fewer inflorescences and flowers, fruitset and normal fruit retained on the tree until maturation will be on the same relative level. In this respect Cuevas et al. (1994) found both enhanced floral quality and increased fruitset percentage for trees in their 'OFF' cycle with low flowering. Furthermore, if the amount of normal fruit yield is not quantitatively related to the number of inflorescences, then fruitset and its distribution within or between inflorescences would differ in accordance with the level of flowering.

Fruit size of the olive is inversely correlated with the level of yield (Hartmann, 1952; Lavee and Spiegel-Roy, 1967; Troncoso et al., 1978). Thus, for the same yield the fruit number might differ considerably. This points to different fruitset potentials in accordance with the fruiting and developmental history of each tree. A major factor in this respect might be the annual shoot growth which is greatly affected by the specific fruit load developing on each tree.

It has been assumed that the fruiting potential of an olive tree is determined by its growing condition and vigor. However, the relation of both inflorescence and flower number to fruitset distribution is not yet clear. Although a general relation between the vegetative tree vigor and yield has been established, the relative fruitset for a given inflorescence density on shoots with different vigor has not yet been defined. An obligatory relation between leaves and flower bud differentiation has been shown with many fruit trees (Westwood, 1988) as well as with olives (Lavee, 1996). On the other hand, no reliable information on the necessity of leaves for fruitset is available.

The effect of embryo presence on fruit survival till harvest is still unclear, as a considerable amount of fruit reaches maturity without a viable embryo. On the other hand Stutte and Martin (1986) reported an obligatory role of the embryo in fruitset up to about 6-8 weeks after flowering. It has also been established that the onset of olive embryo growth occurs 4 weeks after flowering when most of the fruitlet drop has already taken place (Rapoport, 1994). The degree of variability in flower quality within each inflorescence and its relation to potential fruitset and survival is also still insufficiently defined. A wider understanding of the floral biology of the olive in general and of various specific cultivars in particular might be of major importance in controlling and regulating the annual and biennial fruiting habit of this species.

In the present study we tried to determine the role of pre-bloom factors such as flower number, flower position and inflorescence abundance in determining final fruit yield. This study represents part of a comprehensive examination of the determinants of olive fruit production, including the interrelations between flower position and quantity, 
inflorescence abundance and distribution, shoot vigor and load, embryo and seed development as well as the involvement of leaves in olive fruitset and survival until maturation. The resulting series of papers will describe the results of pre- and post-bloom field as well as anatomical-cytological studies of the various flowers and developing young fruits.

\section{Materials and methods}

Two well-developed irrigated orchards with good production in the coastal plain of Israel were chosen for this part of the study. Experiments were carried out annually over a period of 10 years. The study started during the fourth production year of 7-year-old trees. The main cultivar used in most experiments was Manzanillo. The cultivars Barnea, Sevillano, Koronaiki, Santa Caterina, Souri, Kadesh and Maelia (Clone 21) were also included in some studies and for comparison. Branches about $40 \mathrm{~cm}$ long (maximum variation $\pm 4 \mathrm{~cm}$ within each experiment) with full floral differentiation (90-95\% of the buds) were chosen for all experiments of this study. Inflorescence size, length and number of flowers as well as the percent of staminate flowers were determined annually on at least 100 inflorescences for each of the experimental plots and each cultivar. Inflorescences from a minimum of five trees were recorded for each cultivar or plot. The data for each cultivar were grouped and averaged for the whole 10 year period. The effect of the percent of staminate flowers per inflorescence on the amount of fruitset was determined by grouping the data on the amount of those flowers into three distinct groups for three of the cultivars tested. Each staminate flower level group was comprised of at least 100 recorded inflorescences.

The effect of flower number on fruitset was determined by thinning the flowers along the fully-differentiated shoots. Three different methods for $50 \%$ reduction of flower number per shoot were applied: (1) removal of every second inflorescence along the shoot; (2) removal of the distal half of each inflorescence; (3) removal of half of the flowers along the main axis of each inflorescence. The effect of flower number on fruit set was further studied by uniformly thinning the flowers of all inflorescences to levels between $10 \%$ and $100 \%$ of the initial flower number. All shoots used were thinned to a uniform load of 30 inflorescences. As each inflorescence bore about 20 flowers in the tested cultivars (Manzanillo and Santa Catarina), each flower represented about $5 \%$ of the flower load on each inflorescence. For the $10 \%$ flower load two different treatments were prepared: In the first, two lateral flowers were left per inflorescence and in the second, one lateral and the king (terminal) flower were retained.

All floral-removal treatments were performed 5-8 days before flower opening. The initial inflorescence number per shoot varied between 30 and 40 depending on plot, year and cultivar. A total of 50-100 shoots with a minimum of 10 per tree were used in each or any year for every treatment and cultivar. Inflorescence and flower removal were performed with a scissors to avoid tearing damage to the leaves and remaining flowers. The inflorescence removal pattern was always started from the proximal end of the shoot progressing to its apex.

All data were calculated on a multi-year basis and statistical significance determined 
at the $P=0.05$ level using the Duncan test for mean separation. In some experiments the standard error (SE) is recorded. When the standard errors of the treatments within a single experiment were similar a mean standard error ( \pm MSE) for all treatments of that experiment was calculated and used.

\section{Results}

A general description of the inflorescence size and flower-type composition of five cultivars was determined annually, recording their length, number of flowers and percent of staminate flowers (Table 1). The standard error within each year was small and thus uniformity of the inflorescence characteristics high. However the differences between years were extreme, with maximum differences of $30 \%$ in inflorescence length, $21 \%$ in flower number and $42 \%$ in the proportion of male flowers. The annual changes did not always follow the same trend in all cultivars. Thus the standard errors for each cultivar are extremely high and differences between years insignificant. However, the mean of the data for the whole 10 year period represented evident differences. On the other hand, with three cultivars for which we had data on a large scale of at least 1000 inflorescences per cultivar, when inflorescences were grouped in accordance with their yearly average proportion of staminate flowers, it became very clear that the amount of fruitset was not affected by the abundance of staminate flowers in any given group of inflorescences (Table 2). However, within each cultivar only shoots of specified length and inflorescence load were chosen for inflorescence characterization and fruit set determination. Therefore the percent of fruitset per number of perfect flowers might change considerably from year to year in accordance with the level of reproductive bud differentiation and the resulting inflorescence load per shoot.

In order to verify this weak relation between flower number and final fruit load, shoots of five cultivars with uniform length and inflorescence load were annually flower-thinned to $50 \%$ of their natural load. Flower number was reduced by removing half the inflorescences or by both methods of thinning flowers within the inflorescences (along the inflorescence axis or removing the distal half). The amount of fruitset was generally similar (except for cv. Koronaiki) in all treatments as well as in the unthinned control (Table 3). Thus the percent of flowers setting fruit doubled when $50 \%$ of the flowers were removed. The similar fruitset in the two within-inflorescence flower-reduction treatments and the control found in most cultivars also indicates that the percent of

Table 1

Inflorescence characteristics of five olive cultivars. (Mean values of 10 years)

\begin{tabular}{llllll}
\hline & Cultivar & & & & \\
\cline { 2 - 6 } Character & Souri & Manzanillo & Barnea & Maelia & Sevillano \\
\hline Inflorescence length (mm) & 32. & 37 & 40 & 41 & 39 \\
Flowers per inflorescence (no.) & 14.1 & 16.5 & 18.0 & 20.2 & 21.3 \\
Staminate flowers (\%) & 26.3 & 42.0 & 35.1 & 30.2 & 55.5 \\
\hline
\end{tabular}


Table 2

The relationship between the percentage of perfect flowers per inflorescence and fruitset in three olive cultivars. (Inflorescences for each cultivar were arbitrarily grouped according to their annual percentage of perfect flowers into three groups: $a, b$ and $c$ )

\begin{tabular}{|c|c|c|c|c|c|c|}
\hline \multirow{2}{*}{$\begin{array}{l}\text { cv. } \\
\text { Inflorescence } \\
\text { group }\end{array}$} & \multicolumn{2}{|l|}{ Sevillano } & \multicolumn{2}{|l|}{ Souri } & \multicolumn{2}{|l|}{ Manzanillo } \\
\hline & $\begin{array}{l}\text { Perfect } \\
\text { flower }(\%)\end{array}$ & $\begin{array}{l}\text { Fruits per } 100 \\
\text { inflorescences }\end{array}$ & $\begin{array}{l}\text { Perfect } \\
\text { flower }(\%)\end{array}$ & $\begin{array}{l}\text { Fruits per } 100 \\
\text { inflorescences }\end{array}$ & $\begin{array}{l}\text { Perfect } \\
\text { flower }(\%)\end{array}$ & $\begin{array}{l}\text { Fruits per } 100 \\
\text { inflorescences }\end{array}$ \\
\hline$a$ & 5 & 12 & 25 & 27 & 35 & 72 \\
\hline b & 20 & 14 & 45 & 26 & 55 & 69 \\
\hline c & 35 & 13 & 65 & 28 & 75 & 71 \\
\hline MSE & - & 4 & - & 6 & - & 6 \\
\hline
\end{tabular}

inflorescences setting fruit was not affected by the flower-removal pattern. On the other hand, when half the inflorescences were removed in order to reduce the flower number, fruitset on the remaining ones was about double. However this contrasted with the results of cv. Koronaiki in which close to $75 \%$ of the inflorescences set fruit even in the controls. Removing half the inflorescences of that cultivar, which characteristically set more than one fruit even on the unthinned shoots, caused only a partial increase in fruitset within each inflorescence. Thus the total fruit set per shoot was significantly reduced. Reducing the flower number by halving the inflorescences in cvs. Kadesh and Barnea caused a small but statistically significant reduction in total fruit set per shoot. This reduction in fruitset was also significant when calculated on flower-number basis.

The relation between flower number within the inflorescences and fruitset was studied in more detail with cvs. Manzanillo and Santa Caterina. Uniform fully-differentiated branches were thinned to 30 well-developed inflorescences. Every flower represented about $5 \%$ of the floral population of each inflorescence. At the final white stage 6-4 days before opening, their number was reduced to different levels. Inflorescences with only two flowers ( $10 \%$ of control) were divided in two groups: one with and one without the terminal king flower.

Fruitset and its distribution were recorded 2 months after full bloom. Although the level of fruitset was significantly different between the two cultivars the general response to flower number reduction was mostly similar (Fig. 1). In both cultivars removing $40 \%$ of the flowers had no effect on the amount of fruitset. Removal of $60 \%$ of the flowers caused a reduction in the number of developing fruits per shoot. This was more pronounced in cv. Manzanillo than in cv. Santa Caterina. Reducing the flower number on each inflorescence to $20 \%$ of the initial number resulted in both cultivars in an increase of fruitset which in cv. Santa Caterina was even higher than in the unthinned and the up-to- $40 \%$ thinned shoots. The increase in fruitset was mostly due to an increase in the number of inflorescences with more than one fruit. With only two flowers retained per inflorescence, fruit set of cv. Manzanillo was low, and similar in the presence or absence of the king flower. In cv. Santa Caterina the relative fruit set of the two-flower inflorescences was significantly higher, and even more evident when the flowers left on the inflorescence were both lateral.

The interaction between flower and inflorescence number was further studied with the clone Maelia. Shoots of uniform length and inflorescence number were flower-thinned 
Table 3

The effect of halving the flower number by different methods on fruit number and relative fruitset based on flower and inflorescence number. (Results are mean values of experiments carried out in four different 'ON' years)

\begin{tabular}{|c|c|c|c|c|c|c|c|c|c|c|c|c|c|c|c|}
\hline \multirow{3}{*}{$\begin{array}{l}\text { Treatment of } 50 \% \\
\text { flower removal }\end{array}$} & \multicolumn{3}{|c|}{ Manzanillo } & \multicolumn{3}{|l|}{ Kadesh } & \multicolumn{3}{|l|}{ Maelia } & \multicolumn{3}{|l|}{ Barnea } & \multicolumn{3}{|l|}{ Koronaiki } \\
\hline & \multirow{2}{*}{$\begin{array}{l}\text { Fruit per } \\
\text { shoot no. }\end{array}$} & \multicolumn{2}{|c|}{ Fruit set } & \multirow{2}{*}{$\begin{array}{l}\text { Fruit per } \\
\text { shoot no. }\end{array}$} & \multicolumn{2}{|l|}{ Fruit set } & \multirow{2}{*}{$\begin{array}{l}\text { Fruit per } \\
\text { shoot no. }\end{array}$} & \multicolumn{2}{|l|}{ Fruit set } & \multirow{2}{*}{$\begin{array}{l}\text { Fruit per } \\
\text { shoot no. }\end{array}$} & \multicolumn{2}{|l|}{ Fruit set } & \multirow{2}{*}{$\begin{array}{l}\text { Fruit per } \\
\text { shoot no. }\end{array}$} & \multicolumn{2}{|l|}{ Fruit set } \\
\hline & & $\operatorname{Inf}(\%)$ & Fl. $(\%)$ & & Inf. (\%) & Fl. (\%) & & Inf. $(\%)$ & Fl. (\%) & & Inf. (\%) & Fl. (\%) & & Inf. (\%) & $\mathrm{Fl} .(\%)$ \\
\hline Control (100\% flowers) & 9.0 & 28.9 & 1.5 & 4.4 & 22.4 & 1.6 & 10.9 & 38.8 & 1.7 & 17.9 & 44.8 & 2.5 & 21.9 & 74.1 & 5.8 \\
\hline Along each florescence & 9.2 & 29.4 & 3.6 & 4.5 & 22.2 & 2.9 & 11.2 & 40.1 & 4.0 & 18.0 & 45.1 & 4.9 & 19.2 & 73.2 & 10.5 \\
\hline Halving all inflorescence & 10.1 & 31.7 & 3.8 & 3.2 & 18.2 & 2.1 & 10.6 & 43.2 & 3.8 & 14.7 & 36.8 & 4.1 & 20.8 & 77.0 & 11.4 \\
\hline $\begin{array}{l}\text { Removal of half } \\
\text { inflorescence }\end{array}$ & 10.6 & 66.3 & 3.9 & 4.6 & 44.7 & 3.0 & 11.5 & 68.5 & 4.1 & 18.9 & 93.8 & 5.2 & 13.0 & 89.0 & 7.2 \\
\hline LSD at $P=0.05$ & 1.5 & 6.2 & 0.9 & 0.5 & 5.9 & 0.6 & 1.1 & 4.9 & 0.7 & 1.2 & 7.1 & 0.7 & 2.9 & 9.7 & 1.0 \\
\hline
\end{tabular}




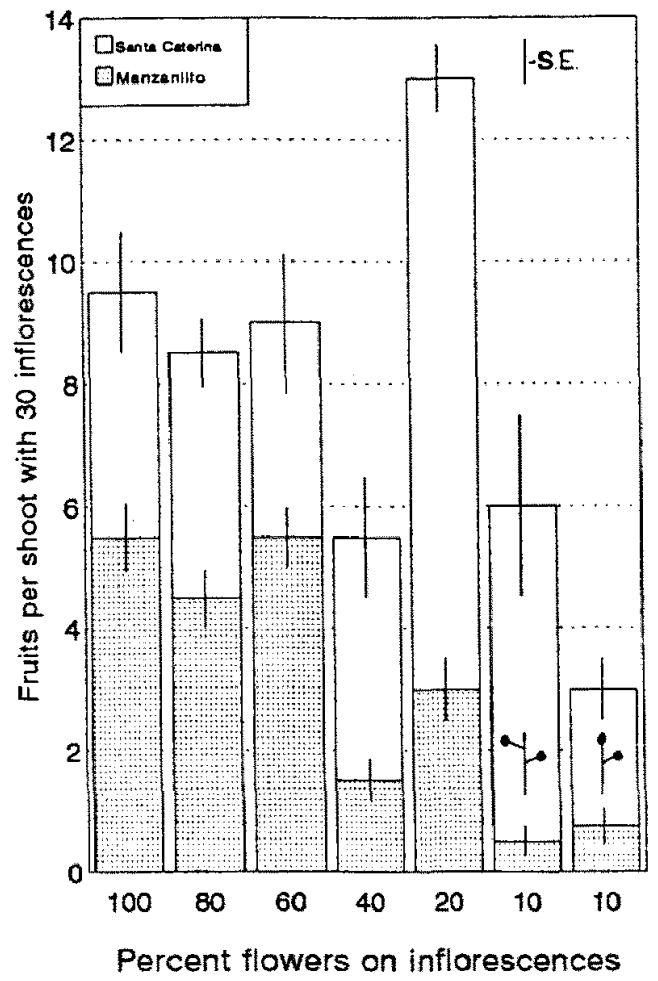

Fig. 1. The effect of flower reduction per inflorescence on fruitset per shoot on cvs. Manzanillo and Santa Caterina. (Shoots with uniform length and inflorescence load were chosen and adjusted to maintain 30 well developed inflorescences. Mean number of flowers per inflorescence was 20 . Terminal-lateral and lateral-lateral flower treatments are indicated graphically in the histogram).

either by removing half the inflorescences or by halving their length. The number of inflorescences with fruit was about $20 \%$ higher when the inflorescences were halved and $20 \%$ lower when their number was reduced than on the unthinned control shoots (Table 4). The total fruit number per shoot was also higher in the halved-inflorescence treatment, but was not reduced when half the inflorescences were removed. The

Table 4

The effect of flower distribution by inflorescence manipulation on fruitset and distribution in the olive clone Maelia. (Results are compiled from four different experiments in ' $O N^{\prime}$ years)

\begin{tabular}{|c|c|c|c|c|c|}
\hline \multirow[t]{2}{*}{ Treatment } & \multirow{2}{*}{$\begin{array}{l}\text { Inflorescence per } \\
\text { shoot (no.) }\end{array}$} & \multirow{2}{*}{$\begin{array}{l}\text { Fruiting } \\
\text { inflorescence } \\
\text { per shoot (no.) }\end{array}$} & \multicolumn{3}{|l|}{ Fruits } \\
\hline & & & $\begin{array}{l}\text { Per } \\
\text { inflorescence } \\
\text { (no.) }\end{array}$ & $\begin{array}{l}\text { Per fruiting } \\
\text { inflorescence } \\
\text { (no.) }\end{array}$ & $\begin{array}{l}\text { Per } \\
\text { shoot } \\
\text { (no.) }\end{array}$ \\
\hline Control & 27.4 & 10.4 & 0,50 & 1.32 & 13.7 \\
\hline $1 / 2$ inflorescence length & 27.8 & 12.0 & 0.54 & 1.25 & 15.1 \\
\hline $1 / 2$ inflorescence number & 12.8 & 8.0 & 1.02 & 1.65 & 13.1 \\
\hline LSD at $P=0.05$ & - & 1.5 & 0.1 & 0.7 & 0.8 \\
\hline
\end{tabular}


Table 5

The effect of flower and inflorescene thinning on the relative amount and distribution of fruitset in the olive clone Maelia. (compiled data of four independent experiments with ' $O N$ ' trees)

\begin{tabular}{|c|c|c|c|c|c|}
\hline \multirow[t]{2}{*}{ Treatment } & \multirow[t]{2}{*}{$\begin{array}{l}\text { Fruits } \\
\text { set }(\%)\end{array}$} & \multirow[t]{2}{*}{$\begin{array}{l}\text { Inforescence } \\
\text { with fruit }(\%)\end{array}$} & \multicolumn{2}{|c|}{$\begin{array}{l}\text { Inflorescence with more } \\
\text { than one fruit }\end{array}$} & \multirow[t]{2}{*}{$\begin{array}{l}\text { Distal inflorescence } \\
\text { with two fruits (\%) }\end{array}$} \\
\hline & & & $\%$ of total & $\%$ of fruitful & \\
\hline Control & 2.4 & 38.0 & 9.7 & 25.7 & 85.7 \\
\hline $1 / 2$ inflorescence length & 5.4 & 43.2 & 10.1 & 23.1 & 76.2 \\
\hline $1 / 2$ inflorescence number & 5.1 & 62.5 & 31.6 & 50.9 & 95.2 \\
\hline LSD at $P=0.05$ & 0.4 & 4.9 & 5.2 & 6.1 & 7.3 \\
\hline
\end{tabular}

difference in final fruit number between the two treatments with reduced flowers was only slightly noticeable and insignificant on the basis of percent fruitset (Table 5). On the other hand the percent of fruitset on the unthinned control shoots was only half that in both thinned treatments. Generally, however, the number of inflorescences per shoot was also not significant in controlling the amount of fruitset. This was apparent from the increased number of fruits per inflorescence when their number was reduced by half (Table 4). In this treatment the number of fruits per inflorescence was doubled when calculated on basis of the existing inflorescence number at bloom and increased by $25 \%$ when based on fruiting inflorescences only. The increase in fruitset per inflorescence, after their number was reduced to half, could be even more strikingly demonstrated when calculated on a relative basis (Table 5). In the Maelia clone the most distal fruiting inflorescence set, in most cases, two fruits. This was somewhat reduced when the inflorescences were halved, and increased when their number was reduced (Table 5). The phenomenon of high incidence of more than one fruit on the most distal fruitful inflorescence has been observed also in some other cultivars such as cvs. Barnea (89.2\%), Manzanillo TI (66.2\%) and Chimlali (82.1\%).

\section{Discussion}

A good commercial yield of olives can be achieved in an ' $\mathrm{ON}$ ' year with a fruit set as low as 1-2\% of the flowers (Martin, 1990). This raises the question of the specific relations between the abundant inflorescences and flower number, their distribution and location to the control of fruit set. The olive has both perfect and staminate flowers, the amount of which is characteristic for each cultivar. However, the ratio between the two types of flowers varies considerably from year to year both due to the developmental and fruiting history of the trees and the specific annual environmental conditions. The amount of fruitset was found in most cases independent from the number of staminate flowers both within and between the various cultivars. This result confirms the early findings such as Brooks (1948) and Rallo and Fernández-Escobar (1985).

Therefore the level of fruitset is determined by the tree-environment relations and is mostly independent of the amount of staminate flowers formed. This conclusion was verified by controlled flower and inflorescence thinning experiments with a number of 
cultivars. We have shown that the response to thinning could be interpreted on the basis of the total number of flowers disregarding the amount of staminate ones among them.

Our results indicate that once the olive trees enters an ' $\mathrm{ON}$ ' year with abundant flowering neither the amount of flowers nor number of inflorescences determine the level of fruitset. Thinning flowers or inflorescences with equal severity did not significantly affect the total number of developing fruits though the distribution on the shoot changed accordingly. In some cases however, such as with cvs. Kadesh and Barnea, reducing the number of flowers number by removing the distil half of each inflorescences caused a slight reduction in the number of developing fruits. This was not the case when the flowers were thinned longitudinally along the inflorescence axis. It could be concluded, therefore, that in those cultivars the distal flowers on the inflorescence were more fruitful than the proximal ones. Thinning by reducing the inflorescence number had no effect on the amount of fruit set except in the case of cv. Koronaiki. This could be attributed to the high fruitfulness of this cultivar, which normally sets more than one fruit on most inflorescences. Thus, a significant reduction in inflorescence number could not be compensated for sufficiently by increasing fruit set on the remaining ones.

The potential of olive cultivars to set more than one fruit per inflorescence was expressed when $50 \%$ flower thinning was performed by removing half the inflorescences before bloom. This also indicates that fruitset is not only controlled by competition within each inflorescence but is dependent also on the global fruiting potential of the tree. It should be noted that the distal fruitful inflorescence sets more than one fruit in most cases also under natural control, unthinned conditions. Excessive flower removal with two cultivars (Manzanillo and Santa Caterina) indicated that about 50\% reduction of the current flower number was the limit for obtaining an unchanged fruitset. In both cultivars fruitset was significantly re-enhanced when only $20 \%$ of the flowers were left intact on each inflorescence. This was particularly the case with cv. Santa Caterina in which fruitset under such conditions was even higher than on control shoots or those with up to $50 \%$ of the flowers removed. In this cultivar lateral flowers had a significant higher fruit setting potential than the king flower. This was not the case with cv. Manzanillo and thus is probably a genetic characteristic. These results indicate the need for further information on the effect of flower load and distribution on the potential and actual fruit set in relation to the current tree growth and reproductive state.

\section{References}

Brooks, R.M., 1948. Seasonal incidence of perfect and staminate olive flowers. Proc. Am. Soc. Hort. Sci., 52 : 213-218.

Cuevas, J., Rallo, L. and Rapoport, H.F., 1994. Crop load effects on floral quality in olive. Scientia Hort., 59: $123-130$.

Griggs, W.H., Hartmann, H.T., Bradley, M.V., Iwakiri, B.T. and Whistler, J.E., 1975. Olive pollination in Califomia. Calif. Agric. Exp. Sta Bull., 869: 50 pp.

Hartmann, H.T., 1952. Spray thinning of Olives. Calif. Agric., 6: 7.

Lavee, S., 1996. Biology and physiology of the olive. In: Encyclopedia of the Olive. Plaza y Janes, Barcelona. (In press). 
Lavee, S. and Spiegel-Roy, P., 1967. The effect of time of application of two growth substances on the thinning of olive fruits. J. Am. Soc. Hort. Sci., 91: 180-186.

Martin, G.C., 1990. Olive flower and fruit production dynamics. Acta Hort., 286: 141-153.

Rallo, L. and Fernández-Escobar, R., 1985. Influence of cultivar and flower thinning within the inflorescences on competition among olive fruits. J. Am. Soc. Hort. Sci., 110: 303-308.

Rallo, L., Martin, G.C. and Lavee, S., 1981. Relationship between abnormal embryo sac development and fruitfulness in olive. J. Am. Soc. Hort. Sci., 106: 813-817.

Rapoport, H.F., 1994. The timing and developmental context of olive embryo growth. Acta Hort., 356: $268-271$.

Rapoport, H.F. and Rallo L., 1991. Post-anthesis flower and fruit abscission in the olive cultivar 'Manzanillo'. J. Am. Soc. Hort. Sci., 116: 720-723.

Stutte, G.W. and Martin, G.C., 1986. Effect of light intensity and carbohydrate reserves on flowering in olive. J. Am. Soc. Hort. Sci., 111: 27-31.

Troncoso, A., Prieto, J. and Liñan, J., 1978. Aclareo quimico de frutos en el olivar Manzanillo de Sevilla. An. de Edafologia y Agrobiologia, 37: 882-893.

Westwood, M.N., 1988. Temperate Zone Pomology. Timber Press, Portland, OR, 428 pp.

Uriu, K., 1959. Periods of pistil abortion in the development of the olive flower. Proc. Am. Soc. Hort. Sci., 73: 194-202. 